\title{
COMBINED USE OF HYALURONIC ACID WITH NANO-BIOACTIVE GLASS ENHANCED BIOCEMENT BASED SILICATE STIMULATED BONE REGENERATIVE CAPACITY IN TIBIAL BONE DEFECTS OF RABBITS: IN-VIVO STUDY
}

\author{
Fatema Aziz Al-Sayed ${ }^{*}$, Radwa Hamed Hegazy $^{1}$, Zeinab Amin Salem ${ }^{1,2}$, \\ Hanan Hassan El-Beheiry ${ }^{3}$
}

${ }^{1}$ Department of Oral Biology, Faculty of Dentistry, Cairo University, Cairo, 11553, Egypt
${ }^{2}$ Department of Oral Biology, Faculty of Dentistry, Ahram - Canadian University, Giza, Egypt
${ }^{3}$ Department of Biomaterials, National Research Centre, Giza, 11553, Egypt

Received - September 11, 2021; Revision - September 29, 2021; Accepted - October 23, 2021 Available Online - October 30, 2021

DOI: http://dx.doi.org/10.18006/2021.9(5).630.638

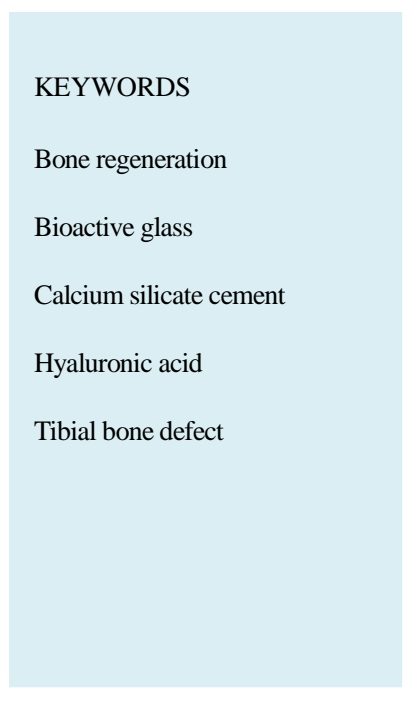

\begin{abstract}
An ideal biomaterial for bone regeneration is a longstanding quest nowadays. This study aimed to evaluate the osteogenic potentiality of nano-bioactive glass enhanced biocement based silicate with or without hyaluronic acid seeded in rabbits' tibial bone defects. For this, 24 male rabbits with two $5 \mathrm{~mm}$ defects ( 1 defect per tibia) were divided into three equal groups. Among the predefined three groups, for the rabbits of group 1(control) bone defects were left untreated while for the members of group 2 defects received nano-bioactive glass enhanced biocement based silicate cement, and group 3 defects received nano-bioactive glass cement mixed with hyaluronic acid. Animals of each group were divided equally for euthanization after 3 and 6 weeks. Bone specimens were processed and examined histologically with histomorphometrically analysis of new bone area percentage. The bone defects in group 3 showed significantly improved osseous healing histologically as compared to the group $1 \& 2$. The morphometric analysis also revealed a significant increase in the new bone area percentage in group 3 as compared to the group 1 and $2(\mathrm{P}<0.05)$. The results of the present study can be concluded that bone defects could be treated with nano-bioactive glass and hyaluronic acid cement. Although, nano-bioactive glass alone was capable of bone regeneration the combination of both had significant regenerative capacity.
\end{abstract}

* Corresponding author

E-mail: fatema-aziz@dentistry.cu.edu.eg (Fatema Aziz Al-Sayed)

Peer review under responsibility of Journal of Experimental Biology and Agricultural Sciences.

Production and Hosting by Horizon Publisher India [HPI] (http://www.horizonpublisherindia.in/).

All rights reserved.
All the articles published by Journal of Experimental Biology and Agricultural Sciences are licensed under a Creative Commons Attribution-NonCommercial 4.0 International License Based on a work at www.jebas.org.

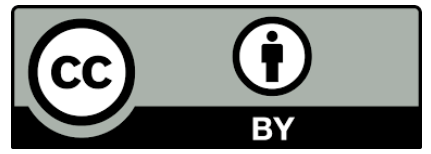




\section{Introduction}

Bone defects represent a serious pathological condition that can cause severe complications and affect vital components of bone. Bone fractures' healing and the union is an obstacle due to precarious blood supply that may complicate the treatment (Rodriguez-Merchan \& Forriol, 2004; Ibrahim, 2006;). The demand for an ideal biosynthetic material with the same structure and function as natural bone used for replacement and repair of bone tissue loss has increased significantly due to the complications of autografts, allografts, and xenografts (Wei et al., 2020). Despite the increasing number of these materials, there is no ideal bone graft substitute (Nandi et al., 2010; Wu \& Chang, 2013). Bone tissue engineering (BTE) is an advanced biomedical technique that is considered an effective approach for bone regeneration and reconstruction of lost bone tissue (Collins et al., 2021). Currently, the paradigm of BTE depends on bone substitute materials that can promote the human body's regenerative capacity in the repair process by stimulating the expression of osteogenic genes. In this regard, the scaffold should be designed as bone tissue "regeneration" rather than mere "replacement"(Salinas et al., 2013). Synthetic materials used for bone regeneration have great potential in clinical applications, this includes metal materials, inorganic non-metallic materials, organic materials, and composites. Bioactive glass (BG) has been applied extensively for bone repair and regeneration as they have shown excellent bone bioactivity and in vivo-bone forming ability (Kaur et al., 2014). The nanoscale of BG showed improvements in its bioactivity, this can be explained by the higher surface area of nanoscale BG that permits rapid release of ions and higher protein adsorption. Previous researches have proven that bone and teeth tissues mineralization was accelerated when these tissues were in contact with nanoscale particles in comparison with micron scaled particles (MačKović et al., 2012). Biocement based silicate was developed more than 20 years ago. The main advantage of silicatebased cement is the fact that silicate plays an essential role in mineralization and gene activation in bone regeneration process. It was reported that silicate can be combined with $\mathrm{Ca}^{2+}$ ions, which have shown its superiority in pre-osseous and osseous tissue repair in vitro and vivo (Zhao et al., 2005; Xu et al., 2008). Calcium silicate has been shown to facilitate cell attachment and integration with opposing hard tissues as well as their active role in bone regeneration. Many researchers reported that biomaterials containing $\mathrm{CaO}-\mathrm{SiO}_{2}$ enhance minerals deposition in addition to bonding capability to living bone and soft tissues through the development of a biologic hydroxyapatite layer on their surface (Wu \& Chang, 2013). However, the degradation of pure tricalcium silicate cement is too slow to match the rate of new bone formation, which limits its application in bone regeneration (Liu et al., 2015). Numerous studies reported the efficacy of combining silicates with other materials to design bioactive biomaterials with better properties for bone tissue regeneration (Abdulghani \& Mitchell, 2019). Hyaluronic acid (HA) acts as an important natural polymer that improves and modifies the biological properties of a synthetic scaffold. HA was found to be capable of binding to extracellular matrix molecules and cell surface receptors. Subsequently, it helped in regulating cellular behavior via control of the tissues' macro- and micro-environments (Chen \& Abatangelo, 1999). It has been proven that HA has a great role in angiogenesis, wound healing, and tissue regeneration. HA-based scaffolds represented a source of osteoinductive elements that can subsequently promote the osteogenic effects of implanted scaffolds (Amini et al., 2012). HA was able to accelerate the degradability rate of scaffolds when added to other biomaterials such as chitosan to coincide with the new bone formation rate (Filho et al., 2021). Several previous reports on the use of nano-bioactive glass, calcium silicate cement and hyaluronic acid in bone regeneration were found. Yet, none incorporated them together as a biocomposite mixture. Therefore, this study aimed to introduce a novel composite scaffold with extrudable nanostructured bioactive glass and calcium silicate based biocement pastes using hyaluronic acid as a solvent, which may serve as an alternative for bone tissue regeneration.

\section{Materials and Methods}

\subsection{Materials}

Tetraethyl orthosilicate (TEOS), triethyl phosphate ethanol (TEP), nitric acid $(65 \%)$ used as a catalyst, calcium nitrate tetrahydrate $\left(\mathrm{Ca}\left(\mathrm{NO}_{3}\right)_{2} \cdot 4 \mathrm{H}_{2} \mathrm{O}\right)$, ammonia $(\mathrm{NHOH})$, and silver nitrate $\left(\mathrm{AgNO}_{3}\right)$ were used to prepare the silver bioactive glass and calcium silicate cement by sol-gel method. Nano-BG particles were prepared by adding TEOS, TEP, calcium nitrate, and silver nitrate in sequence under constant stirring. Forty-five minutes were given for each reagent to react completely. The solution gels were aged for 8 days at room temperature. The gel was subsequently dried at $70{ }^{\circ} \mathrm{C}$ for $72 \mathrm{~h}$ to reach the monolith. The dry gel was fired at $500{ }^{\circ} \mathrm{C}$ for $8 \mathrm{~h}$. The glass system reached was $60 \mathrm{SiO}_{2}: 35 \mathrm{CaO}: 4 \mathrm{P}_{2} \mathrm{O}_{5}: 1 \quad \mathrm{Ag}_{2} \mathrm{O}_{3}$ (Kozon et al., 2016). The novel biocement was prepared by mixing $80 \%$ of calcium silicate cement with $20 \%$ of silver bioactive glass (Lee et al., 2018). Either high molecular weight hyaluronic acid (1750 kDa) (Sigma-Aldrich Merck KGaA, Darmstadt, Germany), or distilled water was used to prepare the cement paste which was subsequently moulded into the critical-sized bone defect (Ahmadzadeh-Asl et al., 2011).

\subsection{Nanocomposite characterization}

Transmission electron microscopy (TEM) was used to analyze the particles size and morphology of nanopowders. The prepared nanocomposites were subjected to TEM analysis by applying JEOL-JEM 2100F to monitor the particle size with an accelerating voltage of $200 \mathrm{kV}$. 


\subsection{Ethical statement}

The study protocol was approved by the Institutional Animal Care and Use Committee (IACUC) - Cairo University with approval number (CU/III/F/46/19). All surgical procedures were performed under general anesthesia, and all efforts were done to minimize suffering.

\subsection{Experimental animals}

This experiment was conducted on 12 weeks old 24 healthy male New Zealand white rabbits weighing about 2.5 to $3.5 \mathrm{~kg}$. Animals were purchased and housed in the animal house Faculty of Medicine, Cairo University. The rabbits were randomly allocated into three groups. Each group consisted of 8 rabbits. Animals were kept in separate cages and maintained under controlled temperature at $25^{\circ} \mathrm{C} \pm 2{ }^{\circ} \mathrm{C}$ with a $12 \mathrm{~h} \mathrm{light/dark} \mathrm{cycle.} \mathrm{They} \mathrm{were} \mathrm{fed} \mathrm{pellets}$ containing several nutritional ingredients including wheat, hay grass, oats, vitamin D, and calcium. The animals were given fresh tap water available ad libitum with good ventilation conditions throughout the experiment.

\subsection{Bone defect preparation}

The surgical procedure was performed under general anesthesia upon intramuscular injection of a combination of $5 \mathrm{mg} / \mathrm{kg} 2 \%$ Xyaline (Xyla-Ject ${ }^{\circledR}$, PhoenixTM, Pharm. Inc., St. Joseph, USA), and $40 \mathrm{mg} / \mathrm{kg}$ Ketamine Chlorhydrate (Ketamine, AmounPharm. Company, Egypt). A single bone defect $5 \mathrm{~mm}$ in diameter was created in each tibia using a round surgical bur coupled to a lowspeed handpiece used under constant copious irrigation with physiological saline solution to prevent the overheating of the periphery of the bone (Doostmohammadi et al., 2019). The bone defect was drilled until the medullary canal was reached. The defects of group 1 (control group) were left untreated (filled with a blood clot), while group 2 defects were filled with nanoBG enhanced biocement based silicate mixed with distilled water. Group 3 defects were packed with nanoBG enhanced biocement based silicate mixed with HA. Postoperatively, the periosteum, muscle, and fascia were repositioned properly over the defects and sutured with resorbable \#2.0 catgut, and the skin was sutured with interrupted \#3.0 silk sutures. Systemic antibiotic Amikacin ${ }^{\circledR} 1.5$ $\mathrm{mg} / \mathrm{kg}$ (Amoun pharmaceutical company, Egypt) was administrated as an intramuscular injection per 12 hours for 1 week (Dang et al., 2019). Analgesic $10 \mathrm{mg} / \mathrm{kg}$ Cataflam (Novartis, Egypt) was administrated to relieve postoperative pain. Topical antibiotic spray Bivatracin (Egyptian Company for Advanced Pharma, Egypt) was applied to avoid local infection. Half of the animals in each group were euthanized with an intra-peritoneal overdose of Ketamine/Xylazine mixture3 weeks postoperatively while the other half was euthanized after 6 weeks (Zhao et al., 2016). Both tibiae were dissected to be free from any soft tissues; the bone specimens including the defect of each group were cut by a disc under constant irrigation to include the entire defect sites.

\subsection{Histological and histomorphometry examination}

Bone specimens were fixed in $10 \%$ calcium formol solution for 48 hours and demineralized in 10\% EDTA (El-Gomhouria Co., Egypt) solution for 4-5 weeks. The specimens were subsequently dehydrated in ascending grades of alcohol, cleared by xylol, and then embedded in paraffin blocks. Serial 5-6 $\mu \mathrm{m}$ paraffin cross sections were prepared and stained with haematoxylin and eosin (H\&E) stain. Histomorphometric analysis of the newly formed bone area percentage was obtained using Leica Owen 500 image analyzer Computer system (Leica Imaging System Ltd., Cambridge, the U.K. in Research unit in faculty of Oral and Dental Medicine, Cairo University). The image analyzer consisted of a colored video camera, colored monitor, hard disc of IBM personal computer connected to the microscope and controlled by Leica Qwen 500 software.

\subsection{Statistical analysis}

The data obtained from the histomorphometric analysis were statistically described in the terms of mean and standard deviation (SD) values. A two-way ANOVA test was used to compare different observation times within the same group. Followed by Tukey's post hoc test to compare multiple 2-group comparisons. The significance level was set at $p<0.05$. Statistical analysis was performed with IBM SPSS 18.0 (Statistical Package for Scientific Studies, SPSS, Inc., Chicago, IL, USA) version 22 for windows.

\section{Results}

\subsection{TEM analysis of nanoBG biocement}

TEM analysis of novel nanoBG silicate based biocement showed the heterogeneous shape of the nanoparticles in form of crystalline dark and amorphous transparent nanoparticles. The average particle size of nanoparticles of the clumped distributions was between 9.46 and $18.36 \mathrm{~nm}$ (figure 1A). While the TEM images of novel biocement mixed with HA showed a uniform distribution with large hydrated cloudy clusters encapsulating many nanoparticles of different morphology. The average nanoparticles size ranged from 12.09 to $15.31 \mathrm{~nm}$ in diameter (figure 1B).

\subsection{Histological (H \& E stain) results}

Three weeks postoperatively, group 1 showed an almost open bone defect with some granulation tissue in the middle of the defect and few newly formed bone trabeculae at the bony edges enclosing large bone marrow cavities in-between (figure 2 A \& B). Thin and interconnected neobone trabeculae were formed around the graft material in group 2 with wide bone marrow cavities in-between 

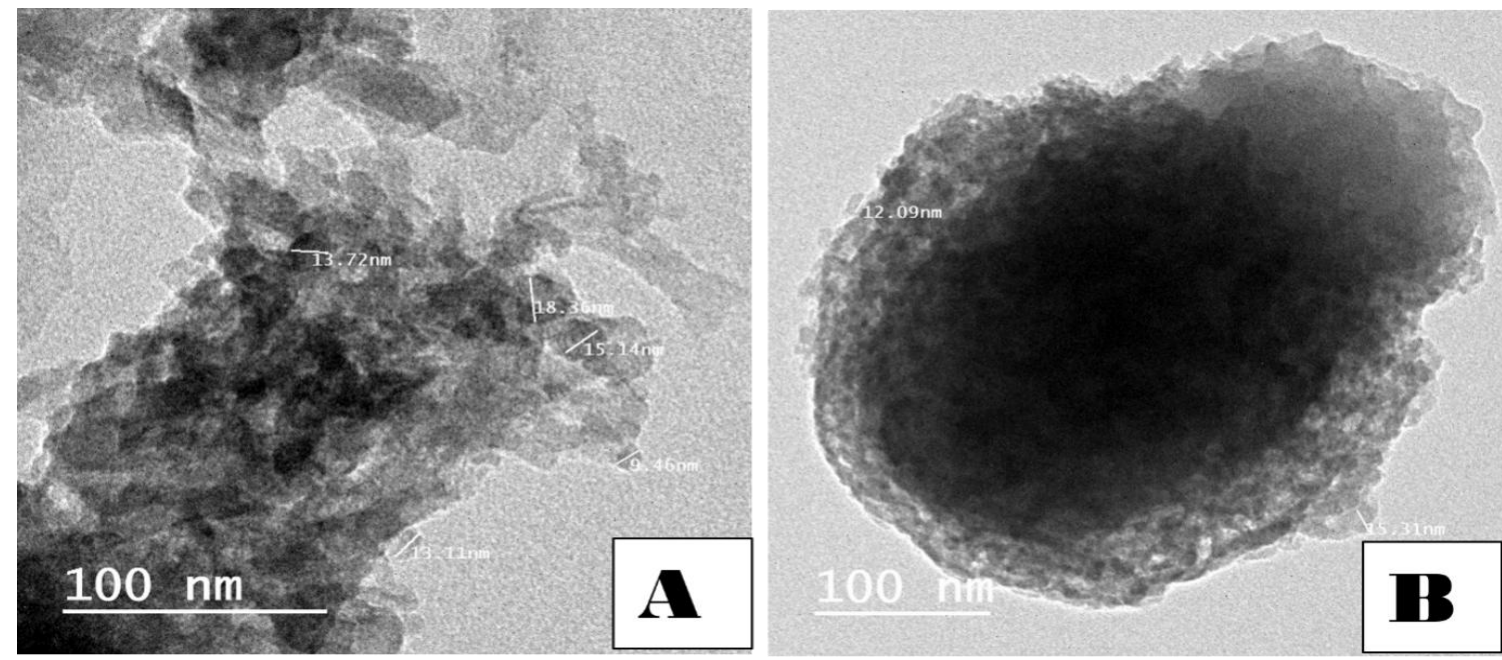

Figure1 TEM image of sliver nanoBG/calcium silicate cement nanopowder (A) TEM image of sliver nanoBG/calcium silicate cement nanopowder mixed with HA (B) (x100 nm)

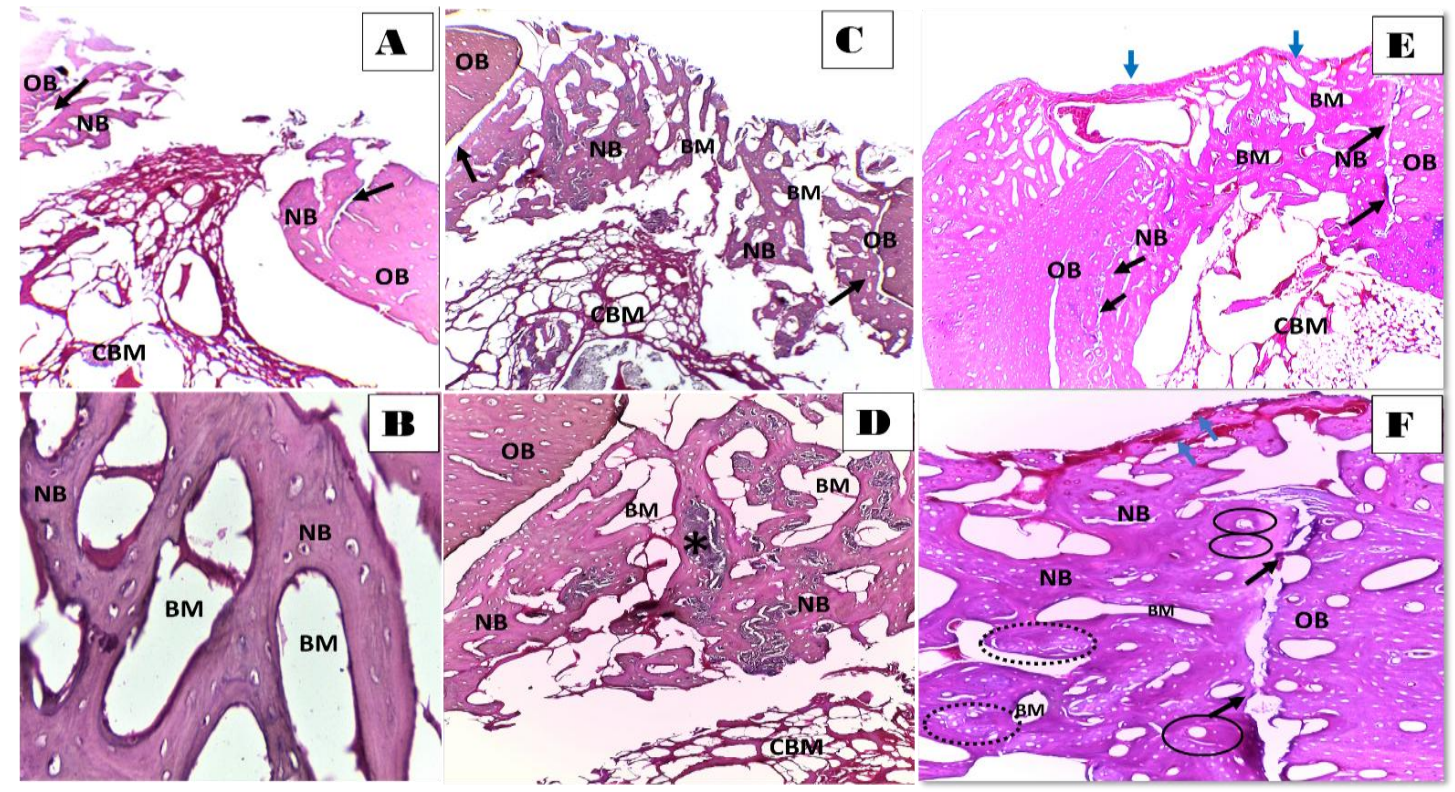

Figure 2 Photomicrographs of H\& E-stained sections of bone defects ( 3 weeks). Group 1 or control group (A \&B), Group 2 (C\&D), Group 3 $(\mathrm{E} \& \mathrm{~F})$. Here OB: old bone, NB: new bone, BM: bone marrow, CBM: central bone marrow, black arrows: interface between old pre-existing and new bone, blue arrows: periosteum, black asterisk: graft material remnants, black circles: primary osteons, dashed black circle: woven bone $(\mathrm{A}, \mathrm{C} \& \mathrm{E} \times 40, \mathrm{~B} \times 400, \mathrm{D} \& \mathrm{~F} \times 100)$

(figure $2 \mathrm{C} \& \mathrm{D}$ ). Group 3 revealed newly formed bone trabeculae filling the defect with thick trabeculation and appearance of primary osteons having wide have rsian canals as well as scattered areas of woven bone. The bone defect showed highly vascularized periosteum coverage. The interface between newly formed bone and old pre-existing bone was about to be sealed with a scalloped border (figure $2 \mathrm{E} \& \mathrm{~F}$ ). Six weeks postoperatively, group 1 defects revealed newly formed interconnecting bone trabeculae filling almost all the defects as compared to the same group at 3 weeks postoperatively.
Dispersed areas of woven bone with different degrees of basophilia were detected (figure 3 A \& B). Group 2 showed bone defect almost filled with newly formed lamellar bone with thick trabeculation enclosing small bone marrow spaces. The indistinguishable interface was observed between old bone and newly formed bone with a significant change in the orientation of the lamellae between old and neobone (figure $3 \mathrm{C} \& \mathrm{D}$ ). Group 3 demonstrated a completely restored defect with densely packed compact bone tissue that could not be distinguished from the old bone with a completely sealed 
interface. Dense compact bone compromised lamellae assumed in concentric arrangement around a have rsian canal, forming a typical osteon (figure $3 \mathrm{E} \& \mathrm{~F}$ ).

\subsection{Histomorphometry}

The histomorphometry analysis of the newly formed bone area percentage between groups during both time intervals showed the highest newly formed bone area percentage in group 3 which revealed a statistically significant increase in the mean of bone area percentage relative to groups 1 and 2. Moreover, all groups showed statistically significant higher newly formed bone area percentage mean value at 6 weeks as compared to 3 weeks $(\mathrm{p}<0.05)$. Tukey's post hoc test revealed a significant difference between each 2 observation times in all groups (figure 4, table 1 and 2).

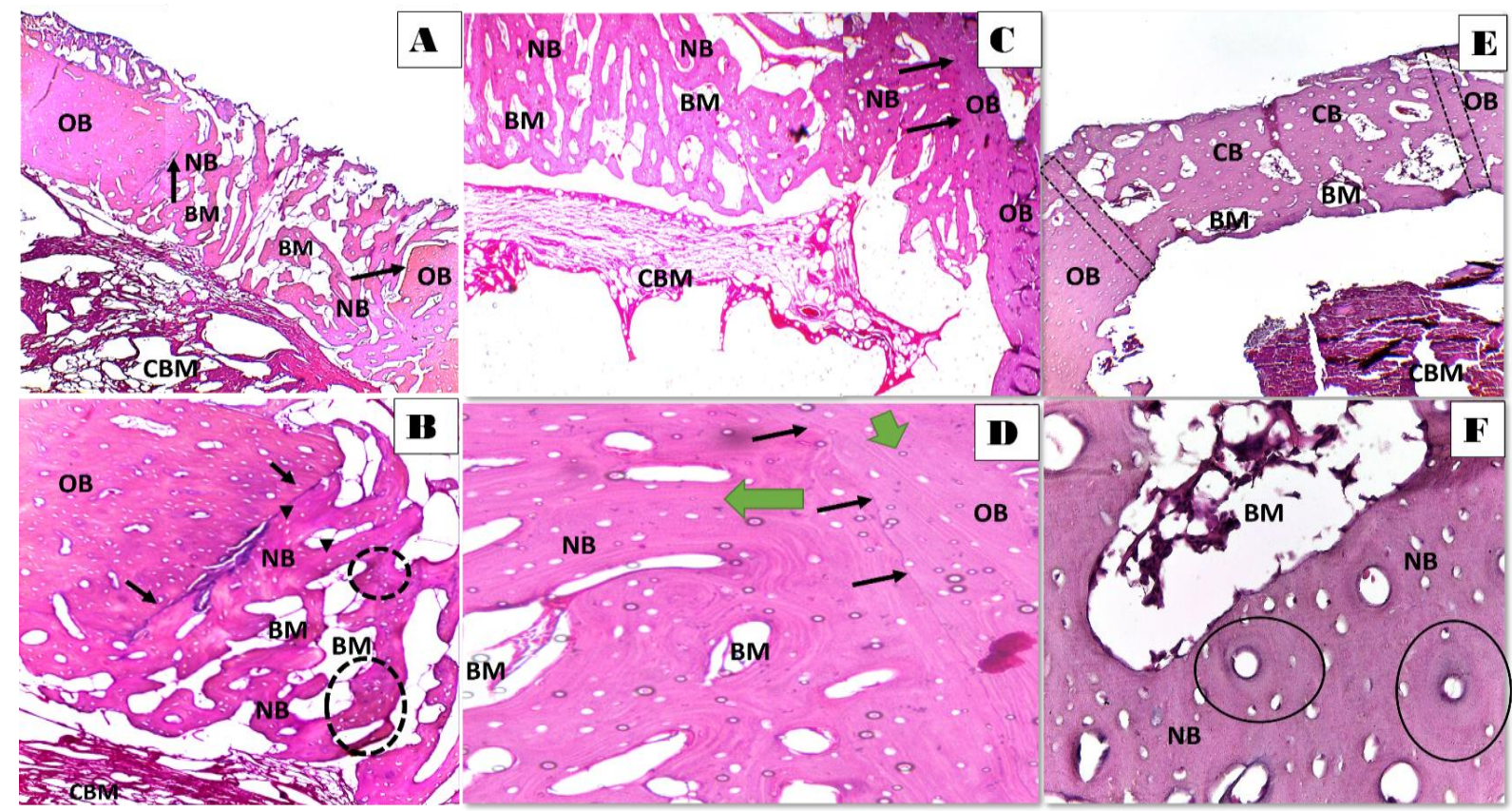

Figure 3 Photomicrographs of H\& E-stained sections of bone defects (6 weeks). Group 1 or control group (A \&B), Group 2(C\&D), Group 3(E\&F), OB: old bone, NB: new bone, BM: bone marrow, CBM: central bone marrow, $\mathrm{CB}$ : compact bone, black arrows and dashed rectangle: interface between old pre-existing and new bone, green arrows: different orientation of bone lamellae, black circles: typical osteons, dashed black circle: woven bone (A, C\&E x40, B x100,D\&F x400).

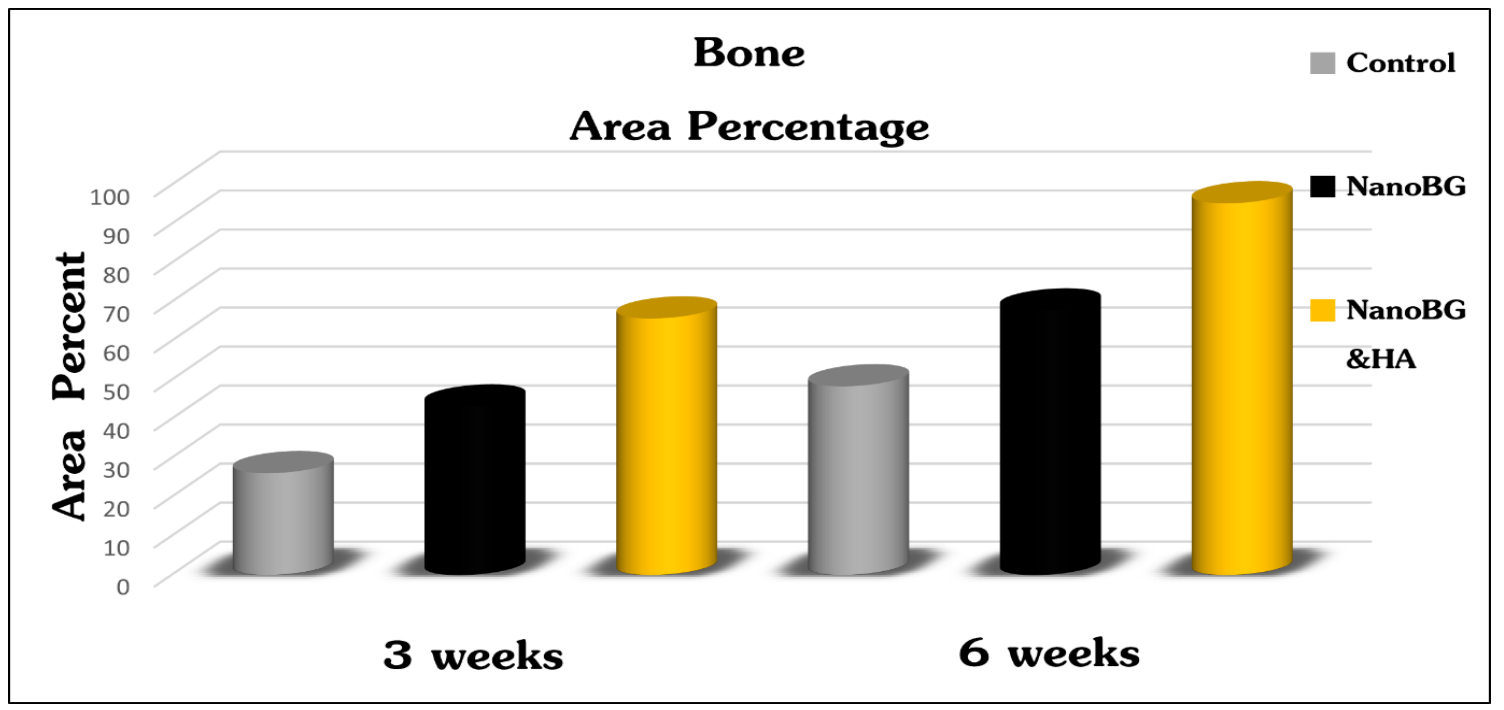

Figure 4 Column chart showing newly formed bone area percentage mean value of with $95 \%$ confidence interval error bars in all groups for 3 and 6 weeks postoperatively

Journal of Experimental Biology and Agricultural Sciences http://www.jebas.org 
Table 1 Newly formed bone area percentage between groups.

\begin{tabular}{|ccccc|}
\hline \multirow{2}{*}{ Duration } & Group & Mean & Standard deviation & Std. Error Mean \\
\hline \multirow{2}{*}{3 weeks } & Group 1 & $26.13^{\mathrm{D}}$ & 3.35 & 1.18 \\
& Group 2 & $43.221^{\mathrm{C}}$ & 2.589 & 0.915 \\
\cline { 2 - 5 } & Group 3 & $65.79^{\mathrm{B}}$ & 4.65 & 1.64 \\
\hline \multirow{2}{*}{ 6 weeks } & Group 1 & $48.40^{\mathrm{C}}$ & 4.17 & 1.47 \\
\cline { 2 - 5 } & Group 2 & $67.84^{\mathrm{B}}$ & 4.31 & 1.52 \\
\cline { 2 - 5 } & Group 3 & $95.317^{\mathrm{A}}$ & 2.039 & 0.721 \\
\hline
\end{tabular}

ANOVA test: Significant means with different superscript letters are significantly different.

Table 2 Newly formed bone area percentage for each group at different observation times

\begin{tabular}{|c|c|c|c|c|c|c|}
\hline Group & Duration & Mean & Standard deviation & Std. Error Mean & T-Value & Adjusted P-Value \\
\hline \multirow{2}{*}{ Group 1} & 3 weeks & 26.13 & 3.35 & 1.18 & & \\
\hline & 6 weeks & 48.40 & 4.17 & 1.47 & 12.22 & $0.000^{*}$ \\
\hline \multirow{2}{*}{ Group 2} & 3 weeks & 43.221 & 2.589 & 0.915 & & \\
\hline & 6 weeks & 67.84 & 4.31 & 1.52 & 13.51 & $0.000^{*}$ \\
\hline \multirow{2}{*}{ Group 3} & 3 weeks & 65.79 & 4.65 & 1.64 & & \\
\hline & 6 weeks & 95.317 & 2.039 & 0.721 & 16.2 & $0.000 *$ \\
\hline
\end{tabular}

Tukey's post hoc test: Pairwise comparison of newly formed bone area \% between different time intervals within the same group. $(*$ Significance level $\mathrm{P} \leq 0.05)$

\section{Discussion}

Before evaluating biomaterials in humans, a perfect bone substitute ought to be tried in vitro and in vivo, to be certain beyond any doubt that it works viably and securely. Therefore, establishing an appropriate animal model is an essential step when assessing the mechanical property and biocompatibility of bone tissue biomaterials (Schlegel et al., 2006). Silica based BG has been exclusively applied for bone repair and regeneration as they showed excellent bone bioactivity and in vivo bone forming ability (Al-Harbi et al., 2021). Numerous works of literature indicate that HA acts primarily to promote healing at fracture sites by stimulating callus formation. Furthermore, HA of a specific molecular weight when used in vitro was reported to significantly increase alkaline phosphatase activity and stimulate osteoblastic cell proliferation and differentiation (Zhai et al., 2020).

The histological results of the current study in the nanoBG group at both time intervals showed better bone regeneration than the control group. They showed interconnected bone trabeculae filling almost all the defect perimeters which appeared thicker with smaller bone marrow cavities 6 weeks postoperatively. Moreover, the newly formed bone area percentage was significantly higher in the nanoBG group than in the control group. BG showed unique properties in bone tissue regeneration by the formation of the carbonated hydroxyapatite layer (HCA) when exposed to biological fluid. This layer is responsible for the strong bonding between bioactive glasses and human bone (Jones et al., 2007). In coincidence with our findings, Abiraman et al., (2002) concluded that after 6 weeks of BG implantation in tibial bone defects in rabbits the periosteal and the endosteal regions were completely closed. As well as Pinto et al., (2013) reported that tibial bone defects implanted with biosilicate ceramics showed highly organized newly formed bone filling the whole defect after 45 days postoperatively. Another study demonstrated that the quantitative woven bone volume was significantly higher in the BG group than in the control group after 20 days of implanting BG in tibial bone defects of rats (Granito et al., 2011).

NanoBG with HA group showed superior histological results than the other 2 groups throughout the whole experiment with the highest newly formed bone area percentage in form of dense uniform and organized compact after 6 weeks. Superior bone regenerative results seen in the nanoBG and HA group could be assumed to the characteristic role of HA in cell adhesion, chemotaxis, differentiation, and proliferation signaled through several macromolecules and especially during wound healing and tissue regeneration (Huang et al., 2003; Prestwich, 2011). Similarly, Shamma et al. (2017) confirmed that the addition of HA into bone graft around dental implants placed in sockets of extracted mandibular third premolar of dogs after 6 weeks showed filled mature well-formed bone with obvious complete osseointegration with the native bone. 
On contrary, El behairy et al. (2019) revealed that HA implanted in combination with biphasic calcium phosphate cement in femoral bone defects of rats didn't give superior bone regeneration in comparison with the cement alone 4 and 10 weeks postoperatively. They explained their findings by assuming that the low molecular weight (less than $1000 \mathrm{kDa}$ ) of the HA used in their study was the reason. The HA ability to enhance the osteogenic and osteoinductive properties of bone graft materials was dependent on its dose and molecular weight. It was found that HA of higher molecular weight (more than $1000 \mathrm{kDa}$ ) promoted mesenchymal stem cells (MSCs) proliferation and differentiation (Huang et al., 2003). This may confirm the osseous regenerative potentiality of HA used in the current study which had a high molecular weight (1750 kDa). However, Kuo et al. (2021) revealed that hybrids of HA with different molecular weights combined with bone grafting material enhanced bone regenerative capacity in rabbit femoral bone defects, suggesting that 50:50 (high molecular weight: low molecular weight) of HA showed ideal degradability and significant new bone formation.

Parallel to our results, Elkarargy, (2013) demonstrated that combining HA to synthetic bone graft increased the newly formed bone area percentage upon implantation in sockets of extracted lower lateral incisors in rabbits when compared with bone graft alone and empty control group after 4 weeks and 8 weeks postoperatively. Moreover, Shirakata et al., (2021) concluded that adding HA either alone or combined with collagen matrix in $5 \mathrm{~mm}$ intrabody defects on the walls of mandibular premolars in dogs enhanced the periodontal wound regeneration. Also, Filho et al., (2021) confirmed that the addition of $1 \%$ HA to the chitosangelatin scaffold in rodents' intrabuccal bone defects revealed improved gingival healing after 21 days with a better degradability rate of scaffolds in comparison to chitosan-gelatin alone.

\section{Conclusions}

From the results of the current study, it can be concluded that the combined use of HA and nanoBG enhanced silicate biocement for osteogenic regeneration of bone defects is a potential alternative treatment for accelerated healing than using these biomaterials alone. This conclusion is a breakthrough in the field of bone graft materials since $\mathrm{BG}$ overcomes the limitations associated with other synthetic and natural bone grafts and makes it a promising bone substitute material in critical bone defects in clinical applications.

\section{Acknowledgments}

The authors are very thankful to all the associated personnel in any reference that contributed to the success of this research, along with deep gratitude to Animal House of Faculty of Medicine Cairo university staff and personnel for their care and endless work dedication.

\section{Funding statement}

This research did not receive any specific grant from funding agencies in the public, commercial, or not-for-profit sectors.

\section{Conflict of interest}

The authors declare that they have no conflict of interest.

\section{References}

Abdulghani S, Mitchell GR (2019) Biomaterials for In Situ Tissue Regeneration: A Review. Biomolecules 9(11): 750.

Abiraman S, Varma HK, Kumari TV, Umashankar PR, John A (2002) Preliminary in vitro and in vivo characterizations of a solgel derived bioactive glass-ceramic system. Bulletin of Materials Science 25(5): 419-429.

Ahmadzadeh-Asl S, Hesaraki S, Zamanian A (2011) Preparation and characterisation of calcium phosphate-Hyaluronic acid nanocomposite bone cement. Advances in Applied Ceramics 110(6): 340-345.

Al-Harbi N, Mohammed H, Al-Hadeethi Y, Bakry AS, Umar A, Hussein MA, Abbassy MA, Vaidya KG, Al Berakdar G, Mkawi EM, Nune M (2021) Silica-based bioactive glasses and their applications in hard tissue regeneration: A review. Pharmaceuticals, 14(2): 1-20.

Amini AR, Laurencin CT, Nukavarapu SP (2012) Bone tissue engineering: Recent advances and challenges. Critical Reviews in Biomedical Engineering 40(5): 363-408.

Chen WYJ, Abatangelo G (1999) Functions of hyaluronan in wound repair. Wound Repair and Regeneration 7(2): 79-89.

Collins MN, Ren G, Young K, Pina S, ReisRL, Oliveira JM (2021) Scaffold Fabrication Technologies and Structure/Function Properties in Bone Tissue Engineering. Advanced Functional Materials, 31(21): 2010609.

Dang LHN, Kim YK, Kim SY, Lim KJ, Bode K, Lee MH, Lee KB (2019) Radiographic and histologic effects of bone morphogenetic protein-2/hydroxyapatite within bioabsorbable magnesium screws in a rabbit model. Journal of Orthopaedic Surgery and Research 14(1): 1-10.

Doostmohammadi A, Karimzadeh Esfahani Z, Ardeshirylajimi A, Rahmati Dehkordi Z (2019) Zirconium modified calcium-silicate-based nanoceramics: An in vivo evaluation in a rabbit tibial defect model. International Journal of Applied Ceramic Technology 16(2): 431-437. 
El behairy R, Hammad H, Ahmed I, Khafagi M (2019) Evaluation of the effect of hyaluronic acid and chitosan biocomposite natural polymers in alveolar ridge preservation: an experimental study in dogs. Egyptian Dental Journal 65(3): 2171-2181.

Elkarargy A (2013) Alveolar Sockets Preservation Using Hydroxyapatite / Beta tricalcium Phosphate with Hyaluronic Acid (Histomorphometric study). Journal of American Science 9(91): $556-563$.

Filho LBC, Silva GAB, GoesAM, de Abreu FAM, Assis MHS, Oliveira ASD, Costa FO, Oliveira PAD (2021) Chitosan-based biomaterial and hyaluronic acid on the repair of intrabuccal bone defects in rats. Journal of the International Academy of Periodontology, 23(2): 138-149.

Granito RN, Rennõ AC, Ravagnani C, Bossini PS, Mochiuti D, Jorgetti V, Driusso P, Peitl O, Zanotto ED, Parizotto NA, Oishi J (2011) In vivo biological performance of a novel highly bioactive glass-ceramic (Biosilicate $\left.{ }^{\circledR}\right)$ A $\quad$ A biomechanical and histomorphometric study in rat tibial defects. Journal of Biomedical Materials Research - Part B Applied Biomaterials, 97 B(1): 139-147.

Huang L, Cheng YY, Koo PL, Lee KM, Qin L, Cheng JCY, Kumta SM (2003) The effect of hyaluronan on osteoblast proliferation and differentiation in rat calvarial-derived cell cultures. Journal of Biomedical Materials Research - Part A 66(4) 880-884.

Ibrahim S (2006) Residual Nonunion following Vascularised Fibular Graft Treatment for Congenital Pseudarthrosis of the Tibia: A Report of Two Cases. Journal of Orthopaedic Surgery 14(2): 226-227.

Jones JR, Gentleman E, Polak J (2007) Bioactive glass scaffolds for bone regeneration. Elements 3(6): 393-399.

Kaur G, Pandey OP, Singh K, Homa D, Scott B, Pickrell G (2014) A review of bioactive glasses: Their structure, properties, fabrication and apatite formation. Journal of Biomedical Materials Research Part A 102(1): 254-274.

Kozon D, Zheng K, Boccardi E, Liu Y, Liverani L, Boccaccini AR (2016) Synthesis of monodispersed Ag-doped bioactive glass nanoparticles via surface modification. Materials 9(4): 225.

Kuo PJ, Yen HJ, Lin CY, Lai HY, Chen CH, Wang SH, Chang WJ, Lee SY, Huang HM (2021) Estimation of the effect of accelerating new bone formation of high and low molecular weight hyaluronic acid hybrid: An animal study. Polymers 13(11):1708.

Lee BS, Lin HP, Chan JCC, Wang WC, Hung PH, Tsai YH, Lee YL (2018) A novel sol-gel-derived calcium silicate cement with short setting time for application in endodontic repair of perforations. International Journal of Nanomedicine 13: 261-271.

Liu W, Zhai D, Huan Z, Wu C, Chang J (2015) Novel tricalcium silicate/magnesium phosphate composite bone cement having high compressive strength, in vitro bioactivity and cytocompatibility. Acta Biomaterialia 21: 217-227.

MačKović M, Hoppe A, Detsch R, Mohn D, Stark WJ, Spiecker E, Boccaccini AR (2012) Bioactive glass (type 45S5) nanoparticles: In vitro reactivity on nanoscale and biocompatibility. Journal of Nanoparticle Research 14(7): 966.

Nandi SK, Mukherjee P, De D (2010) Orthopaedic applications of bone graft \& graft substitutes: A review. Indian Journal of Medical Research 32: 15-30.

Pinto KNZ, Tim CR, Crovace MC, Matsumoto MA, Parizotto NA, Zanotto ED, Peitl O, Rennó ACM (2013) Effects of biosilicate ${ }^{\circledR}$ scaffolds and low-level laser therapy on the process of bone healing. Photomedicine and Laser Surgery 31(6): 252-260.

Prestwich GD (2011) Hyaluronic acid-based clinical biomaterials derived or cell and molecule delivery in regenerative medicine. Journal of Controlled Release 155(2): 193-199.

Rodriguez-Merchan EC, Forriol F (2004) Nonunion: general principles and experimental data. Clinical Orthopaedics and Related Research 419: 4-12.

Salinas AJ, Esbrit P, Vallet-Regí M (2013) A tissue engineering approach based on the use of bioceramics for bone repair. Biomaterials Science 1(1): 40-51.

Schlegel KA, Lang FJ, Donath K, Kulow JT, Wiltfang J (2006) The monocortical critical size bone defect as an alternative experimental model in testing bone substitute materials. Oral Surgery, Oral Medicine, Oral Pathology, Oral Radiology and Endodontology 102(1): 7-13.

Shamma MM, Ayad SS, El-dibany RM, Nagui DA (2017) Evaluation of the Effect of Hyaluronic Acid Mixed With Biphasic Calcium Phosphate on Bone Healing Around Dental Implants (Experimental Study). Alexandria Dental Journal 42(1): 104-107.

Shirakata Y, Imafuji T, Nakamura T, Kawakami Y, Shinohara Y, Noguchi K, Pilloni A, Sculean A (2021) Periodontal wound healing/regeneration of two-wall intrabony defects following reconstructive surgery with cross-linked hyaluronic acid-gel with or without a collagen matrix: a preclinical study in dogs. Quintessence International 0(0): 308-16. 
Wei S, Ma JX, Xu L, Gu XS, Ma XL (2020) Biodegradable materials for bone defect repair. Military Medical Research, 7(1): $1-25$.

Wu C, Chang J (2013) A review of bioactive silicate ceramics. Biomedical Materials 8(3): 032001.

Xu S, Lin K, Wang Z, Chang J, Wang L, Lu J, Ning C (2008) Reconstruction of calvarial defect of rabbits using porous calcium silicate bioactive ceramics. Biomaterials 29(17): 2588-2596.

Zhai P, Peng X, Li B, Liu Y, Sun H, Li X (2020) The application of hyaluronic acid in bone regeneration. International Journal of Biological Macromolecules 151:1224-1239.

Zhao MD, Huang JS, Zhang XC, Gui KK, Xiong M, Yin WP, Yuan FL, Cai GP (2016) Construction of radial defect models in rabbits to determine the critical size defects. PLoS ONE 11(1): e0146301.

Zhao W, Wang J, Zhai W, Wang Z, Chang J (2005) The selfsetting properties and in vitro bioactivity of tricalcium silicate. Biomaterials 26(31): 6113-6121. 